\title{
Risk factors for complicated parapneumonic effusion and empyema on presentation to hospital with community-acquired pneumonia
}

\author{
J D Chalmers, A Singanayagam, M P Murray, C Scally, A Fawzi, A T Hill
}

See Editorial, p 556Royal Infirmary of Edinburgh, Edinburgh, Scotland, UK

Correspondence to: Dr J D Chalmers, Department of Respiratory Medicine, Royal Infirmary of Edinburgh, 51 Little France Crescent, Old Dalkeith Road, Edinburgh EH16 4SA, UK; jamesdchalmers@googlemail.com

Received 30 July 2008 Accepted 10 December 2008 Published Online First 6 January 2009

\begin{abstract}
Background: The aim of this study was to identify key factors on admission predicting the development of complicated parapneumonic effusion or empyema in patients admitted with community-acquired pneumonia. Methods: A prospective observational study of patients admitted with community-acquired pneumonia in NHS Lothian, UK, was conducted. Multivariate regression analyses were used to evaluate factors that could predict the development of complicated parapneumonic effusion or empyema, including admission demographics, clinical features, laboratory tests and pneumonia-specific (Pneumonia Severity Index (PSI), CURB65 (New onset confusion, urea $>7 \mathrm{mmol} / \mathrm{l}$, Respiratory rate $\geqslant 30$ breaths/min, Systolic blood pressure $<90 \mathrm{~mm} \mathrm{Hg}$ and/or diastolic blood pressure $\leq 60 \mathrm{~mm} \mathrm{Hg}$ and age $\geqslant 65$ years) and CRB65 (New onset confusion, Respiratory rate $\geqslant 30$ breaths/min, Systolic blood pressure $<90 \mathrm{~mm} \mathrm{Hg}$ and/or diastolic blood pressure $\leq 60 \mathrm{~mm} \mathrm{Hg}$ and age $\geqslant 65$ years)) and generic sepsis scoring systems (APACHE II (Acute Physiology and Chronic Health Evaluation II), SEWS (standardised early warning score) and systemic inflammatory response syndrome (SIRS)).
\end{abstract}

Results: 1269 patients were included in the study and 92 patients $(7.2 \%)$ developed complicated parapneumonic effusion or empyema. The pneumonia-specific and generic sepsis scoring systems had no value in predicting complicated parapneumonic effusion or empyema. Multivariate logistic regression identified albumin $<30 \mathrm{~g} / \mathrm{l}$ adjusted odds ratio (AOR) 4.55 (95\% Cl 2.45 to 8.45 , $p<0.0001$ ), sodium $<130 \mathrm{mmol} / \mathrm{I}$ AOR 2.70 (1.55 to $4.70, p=0.0005)$, platelet count $>400 \times 10^{9} / /$ AOR 4.09 (2.21 to 7.54, $\mathrm{p}<0.0001$ ), C-reactive protein $>100 \mathrm{mg} / \mathrm{l}$ AOR 15.7 (3.69 to 66.9, $p<0.0001$ ) and a history of alcohol abuse AOR 4.28 (1.87 to $9.82, p=0.0006$ ) or intravenous drug use AOR 2.82 (1.09 to $7.30, p=0.03$ ) as independently associated with development of complicated parapneumonic effusion or empyema. A history of chronic obstructive pulmonary disease was associated with decreased risk, AOR 0.18 (0.06 to 0.53, $p=0.002$ ). A 6-point scoring system using these combined variables had good discriminatory value: area under the receiver operator characteristic curve (AUC) $0.84(95 \% \mathrm{Cl} 0.81$ to $0.86, \mathrm{p}<0.0001)$.

Conclusion: This study has identified seven clinical factors predicting the development of complicated parapneumonic effusion or empyema. Independent validation is needed.

Complicated parapneumonic effusions and empyema are key complications of communityacquired pneumonia necessitating prolonged treatment, intercostal drainage and frequently surgical management, leading to prolonged hospital stay. ${ }^{1-3}$

In 1980, Light and colleagues established the criteria that are now used to define complicated parapneumonic effusions but found no reliable clinical or radiological features to predict which patients with community-acquired pneumonia will develop complicated parapneumonic effusions or empyema. ${ }^{4}$ Only small studies have been available to date.

Pneumonia severity scores including CURB65 (New onset confusion, urea $>7 \mathrm{mmol} / \mathrm{l}$, Respiratory rate $\geqslant 30$ breaths/min, Systolic blood pressure $<90 \mathrm{~mm} \mathrm{Hg}$ and/or diastolic blood pressure $\leq 60 \mathrm{~mm} \mathrm{Hg}$ and age $\geqslant 65$ years), CRB65 (New onset confusion, Respiratory rate $\geqslant 30$ breaths/min, Systolic blood pressure $<90 \mathrm{~mm} \mathrm{Hg}$ and/or diastolic blood pressure $\leq 60 \mathrm{~mm} \mathrm{Hg}$ and age $\geqslant 65$ years) and the Pneumonia Severity Index (PSI) ${ }^{5-9}$ have been used on admission to predict 30-day mortality, but no-one to date has studied their utility to predict the development of complicated parapneumonic effusion or empyema.

The aim of this study was to identify key factors predicting the development of complicated parapneumonic effusion or empyema in patients admitted with community-acquired pneumonia.

\section{METHODS}

We prospectively identified all patients, admitted between January 2005 and January 2008 to NHS Lothian, UK, with a primary diagnosis of communityacquired pneumonia. Ethical approval was obtained from the Lothian research ethics committee.

The inclusion criteria and study protocol have been described previously. ${ }^{9}$ Exclusion criteria were hospital-acquired pneumonia (development of symptoms $>48 \mathrm{~h}$ after admission to hospital or discharge from an acute care facility within 14 days of admission); active thoracic or extrathoracic malignancy; metastatic infection from a non-pulmonary source; immunosuppression (including patients prescribed long-term prednisolone, methotrexate, azathioprine or antitumour necrosis $\alpha$ (TNF $\alpha$ ) treatment); solid organ transplant; previous empyema or chronic pleural effusion due to a cause other than pneumonia; recent thoracic surgery; and patients for whom active treatment is not considered appropriate (eg, palliative care).

\section{Identification of parapneumonic effusions}

All patients had a standard chest radiograph within $24 \mathrm{~h}$ of admission, and this was repeated if clinically indicated. All patients with pleural 
Figure 1 Method of identification of cases of complicated parapneumonic effusion and empyema. LDH, lactate dehydrogenase.

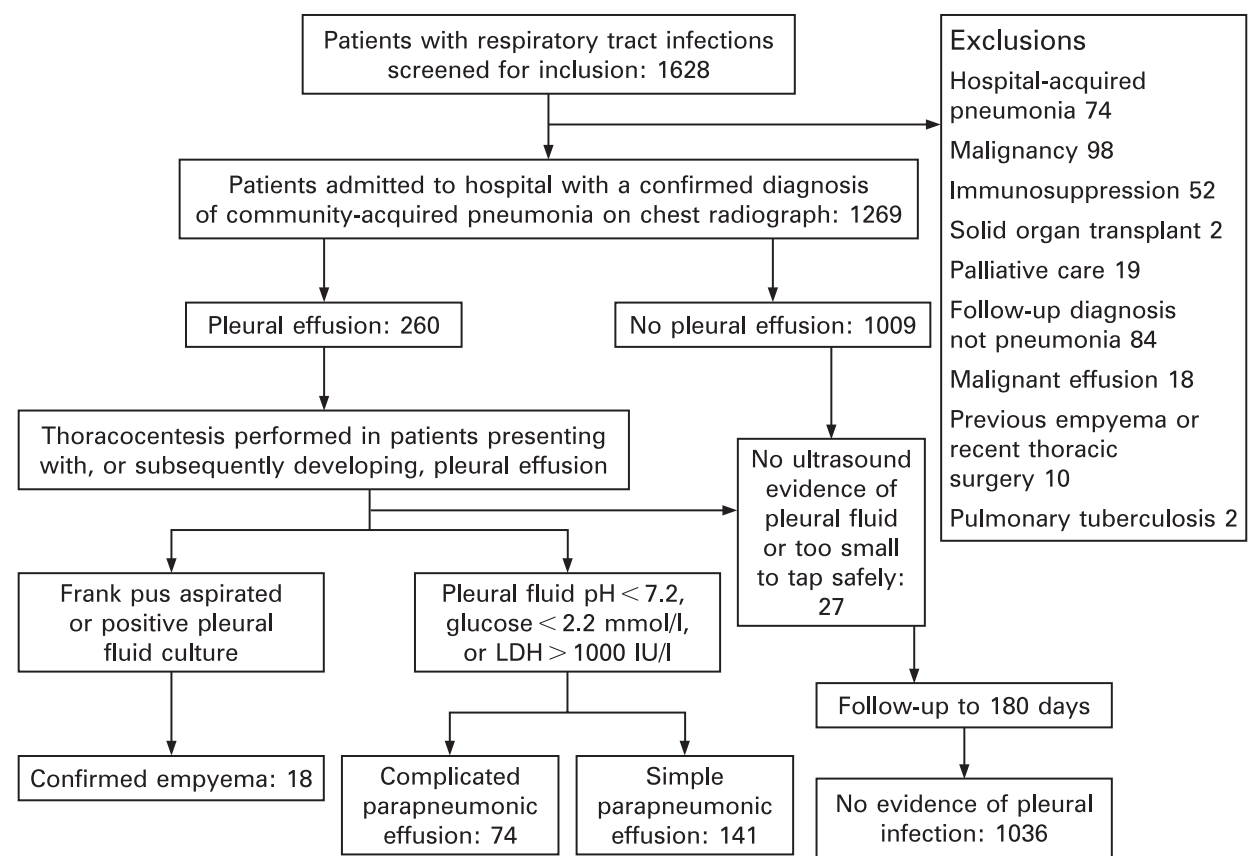

effusions underwent clinical assessment and thoracic ultrasound if required. All patients with pleural effusion underwent thoracocentesis, except in small pleural effusions thought unsafe for pleural aspiration from thoracic ultrasound. Fluid was analysed for $\mathrm{pH}$, protein, lactate dehydrogenase (LDH), glucose, Gram stain, culture and cytology. In patients with empyema too viscous to analyse, the sample was sent for Gram stain and microbiological culture only.

\section{Definition of complicated pneumonia and empyema}

The primary outcome was development of complicated parapneumonic effusion or empyema. Complicated parapneumonic effusion was defined according to the criteria described by Light and colleagues ${ }^{4}$ as at least one of pleural fluid $\mathrm{pH}<7.2, \mathrm{LDH}$ $>1000 \mathrm{IU} / 1$ or glucose $<2.2 \mathrm{mmol} / \mathrm{l}$. Empyema was defined as frank pus aspirated from the pleural space or positive Gram stain/culture for pathogenic organisms.

For the purposes of comparison, early development of complicated parapneumonic effusion/empyema was defined as diagnosis $\leqslant 72 \mathrm{~h}$ after admission to hospital. Late development of empyema was defined as diagnosis $>72 \mathrm{~h}$ after admission. The date of diagnosis of empyema was taken to be the date of the confirmatory thoracocentesis.

\section{Severity scores}

We evaluated factors that could predict the development of complicated parapneumonic effusion or empyema, including admission demographics, clinical features, laboratory tests and severity scores. The pneumonia-specific scores included the PSI, ${ }^{7}$ CURB65 $5^{5}$ and CRB65. ${ }^{5}$ The generic sepsis scores included the APACHE II (Acute Physiology and Chronic Health Evaluation II) score, ${ }^{10}$ SIRS (systemic inflammatory response syndrome) criteria $^{11}$ and SEWS (standardised early warning score) score. ${ }^{12}$ For the purposes of calculating the values of predictive tests the following were used to define "severe" for each scoring system, PSI $\geqslant 4$; CURB65 $\geqslant 3$; CRB65 $\geqslant 3$; SIRS severe sepsis or septic shock; SEWS $\geqslant 4$. The APACHE score is a progressive scale with increasing estimated death rates for increasing scores. For purposes of comparison in this study "severe" was arbitrarily set at $>9$ points prior to the study which equates to a $>9.9 \%$ risk of death.

\section{Statistical analysis}

Demographic, clinical, laboratory, radiological and other variables were converted to binary variables based on cut-off points identified in the community-acquired pneumonia literature, primarily studies focusing on mortality. The relative risks were expressed as adjusted odds ratios (AORs) and 95\% CI. All variables that were statistically significant in the univariate analysis with a $p$ value $<0.05$ were entered in a multivariable model with a stepwise approach. Multicollinearity was assessed by using bivariate linear regression between variables and using the variance inflation factor. A variance inflation factor (VIF) of $<2.5$ was regarded as excluding significant interactions. ${ }^{13}$

The value of tests for predicting outcomes was compared using the area under the receiver operator characteristic curve (AUC).$^{14}$ For interpretation of these values the following is widely accepted: AUC $0.50-0.59$, no value of test; $0.60-0.69$, poor discriminatory value; $0.70-0.79$, moderate discriminatory value; $0.80-0.89$, good discriminatory value; $0.90-1.00$, excellent discriminatory value.

The $\chi^{2}$ test was used to compare categorical variables, and for continuous variables the Mann-Whitney $U$ test was used for two groups. Data are presented as number (percentage) or median (interquartile range (IOR)). A $p$ value of $<0.05$ was considered statistically significant for each analysis.

\section{RESULTS}

A total of 1628 patients were considered for inclusion and 359 patients were excluded (see fig 1); 1269 patients were therefore included in the study. Ninety-two patients $(7.2 \%)$ met the criteria for complicated parapneumonic effusion (74 patients, $5.8 \%$ ) or empyema (18 patients, $1.4 \%$ ).

Baseline characteristics and comorbidities of the study population are shown in table 1. Pleural fluid characteristics were as follows for patients developing complicated parapneumonic 
Table 1 Baseline characteristics of the study population

\begin{tabular}{lllll}
\hline $\begin{array}{l}\text { Baseline characteristics } \\
\text { and comorbidities }\end{array}$ & $\begin{array}{l}\text { Study } \\
\text { population }\end{array}$ & CPE/Emp & $\begin{array}{l}\text { Uncomplicated } \\
\text { pneumonia }\end{array}$ & p Value \\
\hline No & 1269 & 92 & 1177 & \\
Age (years) & $66(51-78)$ & $57(41-68)$ & $67(51-78)$ & $<0.0001$ \\
Gender (\% male) & $49.2 \%$ & $57.6 \%$ & $48.5 \%$ & 0.1 \\
Chronic cardiac disease & $19.1 \%$ & $9.8 \%$ & $19.8 \%$ & 0.02 \\
Liver disease & $5 \%$ & $10.9 \%$ & $4.6 \%$ & 0.009 \\
Neurological disease & $11.1 \%$ & $2.2 \%$ & $11.8 \%$ & 0.01 \\
Chronic renal failure & $6 \%$ & $6.5 \%$ & $5.9 \%$ & 0.8 \\
Diabetes mellitus & $10.2 \%$ & $6.5 \%$ & $10.5 \%$ & 0.2 \\
COPD & $20.3 \%$ & $4.3 \%$ & $21.5 \%$ & 0.0005 \\
Chronic alcohol abuse & $5.5 \%$ & $13 \%$ & $4.9 \%$ & 0.002 \\
Intravenous drug use & $3 \%$ & $10.9 \%$ & $2.4 \%$ & $<0.0001$ \\
Current smokers & $34.2 \%$ & $44.6 \%$ & $33.4 \%$ & 0.04
\end{tabular}

The $\mathrm{p}$ value is derived from comparison between patients with CPE/Emp and patients with uncomplicated pneumonia using the $\chi^{2}$ test, except for age (Mann-Whitney $\mathrm{U}$ test).

$\mathrm{COPD}$, chronic obstructive pulmonary disease; $\mathrm{CPE} / \mathrm{Emp}$, complicated parapneumonic effusion or empyema.

effusion or empyema: median $\mathrm{pH} 7.1$ (IOR 7.0-7.2); glucose $1.0 \mathrm{mmol} / \mathrm{l}$ (0.6-2.5), protein $40 \mathrm{~g} / \mathrm{l}$ (35-46); LDH $2900 \mathrm{IU} / 1$ (1035-4720).

\section{Microbiology of empyema}

A positive pleural fluid culture was found in 16/92 patients. The Streptococcus milleri group ( $S$ intermedius, $S$ constellatus and $S$ mitis) were the most frequent organisms isolated in six cases. $S$ pneumoniae was isolated in two cases and other streptococci were isolated in four cases. Two samples grew anaerobic organisms. Staphylococcus aureus and Enterobacteriaceae were isolated in a single case. Ninety-two patients (100\%) had received antibiotic treatment prior to pleural aspiration. The organisms isolated are shown in fig 2 .

\section{Outcomes in patients with and without complicated parapneumonic effusion or empyema}

Patients with complicated parapneumonic effusion or empyema had longer length of stay and higher rates of intensive care unit admission compared with patients without these complications. The 30-day mortality rate was not significantly different between groups (table 2).

Ninety-two patients (100\%) meeting the criteria for complicated parapneumonic effusion or empyema had an intercostal drain inserted for drainage of their effusion. Intrapleural fibrinolytics were not used. Eighteen patients failed to improve with chest tube drainage and subsequently required surgical thoracotomy. Two of these patients died within 30 days of admission. A further six patients died within 30 days and had not received thoracotomy. Twenty-four patients (22\%) were therefore categorised as failure of medical treatment.

\section{Recognised severity scores}

Recognised severity scores were compared for their ability to predict the development of complicated parapneumonic effusion or empyema. All had low AUCs for the prediction of complicated parapneumonic effusion and empyema (see fig 3 and table 3 .

The positive predictive value, negative predictive value, sensitivity, specificity and AUC for each rule are shown in table 3.

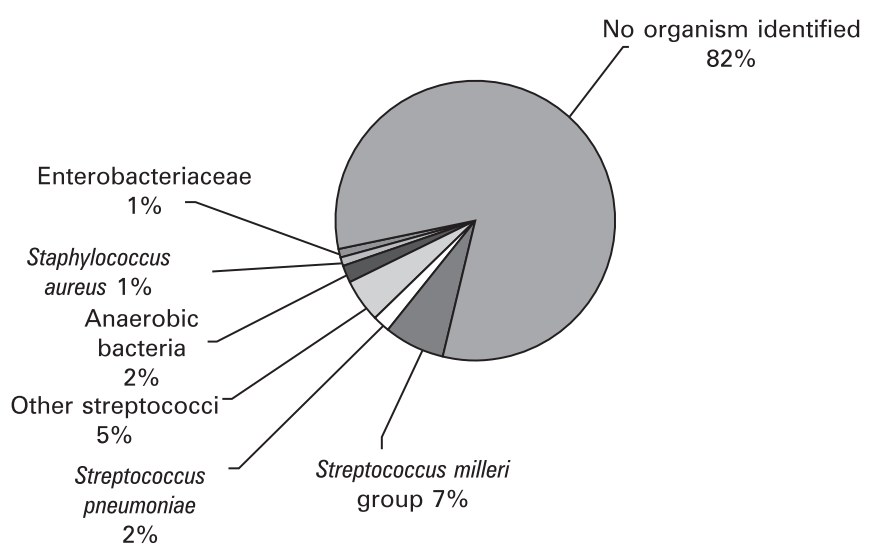

Figure 2 Microbiology of empyema.

\section{Prediction of development of complicated parapneumonic effusion or empyema}

Complete clinical data were available for all patients, with the exception of arterial blood gas measurements which were not performed in all patients and so were not included in the multivariate analysis.

On multivariate logistic regression, low serum albumin $<30 \mathrm{~g} / \mathrm{l}$, elevated C-reactive protein (CRP) $>100 \mathrm{mg} / \mathrm{l}$ and platelet count $>400 \times 10^{9} / 1$, low serum sodium $<130 \mathrm{mmol} / \mathrm{l}$, intravenous drug use or chronic alcohol abuse were all were identified as independent predictors of the subsequent development of complicated parapneumonic effusion or empyema. A history of chronic obstructive pulmonary disease (COPD) was associated with decreased risk (table 4). No strong correlations were identified between predictors. No VIF was $>2.5$ and the average VIF was 1.03

\section{Clinical application of the data}

A scoring system was developed to assess if the identified "risk factors" for development of complicated parapneumonic effusion or empyema could be applied clinically. Each risk factor identified in the multivariate analysis that predicts complicated parapneumonic effusion or empyema (table 5) was given a numerical value (+1 point); 1 point was subtracted for the presence of COPD. The incidence of complicated parapneumonic effusion or empyema according the number of risk factors is shown in table 5.

Although in theory this was a 6-point score, in practice no patients had the maximum of 6 points. The resultant scoring system was analysed using the AUC. There appeared to be a clear separation between patients with 1 point $(2.4 \%)$ and patients with higher scores $(\geqslant 11.8 \%)$, and so performance characteristics were calculated with these values representing high and low risk of developing complicated parapneumonic effusion and empyema.

Table 2 Outcomes in patients with complicated parapneumonic effusion or empyema

\begin{tabular}{llll}
\hline & $\begin{array}{l}\text { Complicated } \\
\text { parapneumonic } \\
\text { effusion/empyema }\end{array}$ & $\begin{array}{l}\text { No complicated } \\
\text { parapneumonic } \\
\text { effusion/empyema }\end{array}$ & p Value \\
\hline Length of stay (days) & $16(11-26)$ & $5(2-10)$ & $<0.0001$ \\
$\begin{array}{l}\text { Intensive care unit } \\
\text { admission }\end{array}$ & $21.7 \%$ & $7.7 \%$ & $<0.0001$ \\
30-Day mortality & $8.7 \%$ & $8.4 \%$ & 0.9
\end{tabular}

The $p$ values refers to comparisons between patients with and without complicated parapneumonic effusion and empyema using the $\chi^{2}$ test, except for length of stay (Mann-Whitney U test). 


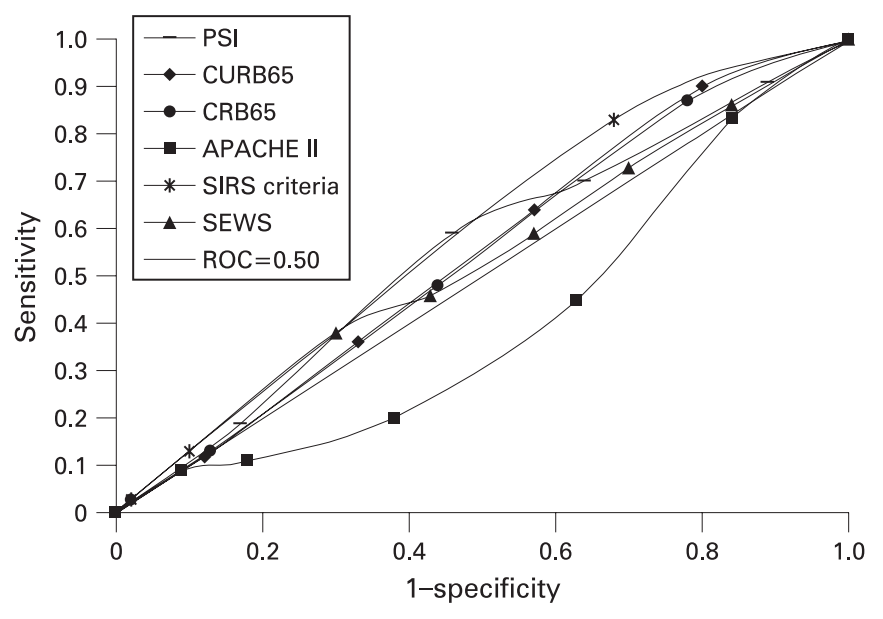

Figure 3 Receiver operator characteristic (ROC) curves for widely used severity scores and development of complicated parapneumonic effusion or empyema. APACHE II, Acute Physiology and Chronic Health Evaluation II; CRB65, New onset confusion, Respiratory rate $\geqslant 30$ breaths/min, Systolic blood pressure $<90 \mathrm{~mm} \mathrm{Hg}$ and/or diastolic blood pressure $\leq 60 \mathrm{~mm} \mathrm{Hg}$ and age $\geqslant 65$ years; CURB65, New onset confusion, urea $>7 \mathrm{mmol} / \mathrm{l}$, Respiratory rate $\geqslant 30$ breaths $/ \mathrm{min}$, Systolic blood pressure $<90 \mathrm{~mm} \mathrm{Hg}$ and/or diastolic blood pressure $\leq 60 \mathrm{~mm} \mathrm{Hg}$ and age $\geqslant 65$ years; SEWS, standardised early warning score; SIRS, systemic inflammatory response syndrome.

For predicting complicated parapneumonic effusion or empyema, using $\geqslant 2$ point as the cut-off, the sensitivity is $87.0 \%$, specificity is $68.3 \%$, positive predictive value is $17.7 \%$, negative predictive value is $98.5 \%$ and AUC is 0.84 (0.81 to 0.86 ), $p<0.0001$ (fig 4). This score was superior to all of the severity scores in table 3 for prediction of complicated parapneumonic effusion or empyema ( $p<0.0001$ for all analyses).

Early versus late complicated parapneumonic effusion/empyema Twenty-two patients (24\%) had the diagnosis of complicated parapneumonic effusion or empyema made within $72 \mathrm{~h}$ of admission. The AUC for the derived score was 0.86 (0.81 to 0.91) for prediction of early complicated parapneumonic effusion/empyema and the AUC was 0.83 (0.80 to 0.86) for prediction of late complicated parapneumonic effusion/ empyema.

\section{DISCUSSION}

This study has identified seven key features that can determine patients at risk of development of complicated parapneumonic effusion or empyema. Low serum albumin $<30 \mathrm{~g} / \mathrm{l}$, CRP
$>100 \mathrm{mg} / \mathrm{l}$, platelet count $>400 \times 10^{9} / 1$, serum sodium $<130 \mathrm{mmol} / \mathrm{l}$, intravenous drug use and chronic alcohol abuse were all were identified as independent predictors of the subsequent development of complicated parapneumonic effusion or empyema. A history of COPD was found to be associated with decreased risk.

Using this information, this study has provided proof of the concept that complicated parapneumonic effusion and empyema can be predicted by deriving a scoring system with good predictive value. The presence of $\geqslant 2$ of the above risk factors has a $87 \%$ sensitivity for detection of complicated parapneumonic effusion or empyema, and a score of $<2$ gives a negative predictive value of $98.5 \%$. The scoring system had "good" performance characteristics for predicting both early and late parapneumonic effusion and empyema. This scoring system now requires independent validation.

Although in univariate analysis, patients with complicated parapneumonic effusion and empyema were younger, more likely to be male and more likely to be current smokers, these differences were not significant in the multivariate analysis.

The risk factors identified in this study are supported by the existing literature. Alcohol abuse is the most common disorder reported in patients with empyema. ${ }^{15}{ }^{16}$ Aspiration of gastric contents and the failure to seek prompt medical attention are two mechanisms that have been proposed to explain this. This may also in part explain the increased incidence of patients with a history of intravenous drug use. There is strong evidence that inflammatory markers are elevated in patients with parapneumonic effusions and empyema, as pleural inflammation is the characteristic feature of these diseases. ${ }^{17}$ In the present study CRP $>100 \mathrm{mg} / \mathrm{l}$ was strongly associated with the development of empyema or complicated parapneumonic effusion. It is well recognised that patients with an elevated CRP on admission that fails to fall with treatment are at increased risk of complicated parapneumonic effusion or empyema. ${ }^{18-20}$ Elevated platelet count is also well recognised in acute and chronic infections. ${ }^{21}$ Empyema is a recognised cause of the syndrome of inappropriate antidiuretic hormone secretion (SIADH), ${ }^{22}$ but hyponatraemia is also recognised in severe community-acquired pneumonia without SIADH. ${ }^{23}$ Hypoalbuminaemia is well recognised in severe community-acquired pneumonia as well as being associated with the development of empyema. ${ }^{73} 24$

The finding that COPD was associated with a decreased risk of complicated parapneumonic effusion and empyema is intriguing. There are compelling reasons to believe that patients with COPD should have increased mortality from pneumonia, but prognostic studies to date have found that this is not the case. ${ }^{73}$ Authors have speculated that the local pulmonary inflammation present in patients with COPD may produce a

Table 3 Severity scores and prediction of complicated pneumonia

\begin{tabular}{lllllll}
\hline Prediction tool & PPV (\%) & NPV (\%) & Sensitivity (\%) & Specificity (\%) & AUC (95\% CI) & p Value \\
\hline PSI & 8.8 & 94.2 & 57.6 & 53.4 & $0.55(0.52$ to 0.58$)$ & 0.1 \\
CURB65 score & 7.5 & 92.9 & 33.7 & 67.5 & $0.54(0.51$ to 0.57$)$ & 0.2 \\
CRB65 score & 4.4 & 92.2 & 9.8 & 83.5 & $0.52(0.49$ to 0.55$)$ & 0.5 \\
APACHE II score & 5.7 & 90.2 & 47.8 & 37.7 & $0.41(0.38$ to 0.44$)$ & 0.002 \\
SIRS & 8.2 & 92.9 & 15.2 & 86.7 & $0.57(0.54$ to 0.60$)$ & 0.03 \\
SEWS & 7.9 & 93.2 & 45.7 & 58.2 & $0.53(0.50$ to 0.56$)$ & 0.3 \\
\hline
\end{tabular}

The $\mathrm{p}$ value refers to comparison between the receiver operator characteristic curve and the null hypothesis.

APACHE II, Acute Physiology and Chronic Health Evaluation II; AUC, area under the receiver operator characteristic curve; CRB65, New onset confusion, Respiratory rate $\geqslant 30$ breaths/min, Systolic blood pressure $<90 \mathrm{~mm} \mathrm{Hg}$ and/or diastolic blood pressure $\leq 60 \mathrm{~mm} \mathrm{Hg}$ and age $\geqslant 65$ years; CURB65, New onset confusion, urea $>7 \mathrm{mmol} / \mathrm{l}$, Respiratory rate $\geqslant 30$ breaths/min, Systolic blood pressure $<90 \mathrm{~mm} \mathrm{Hg}$ and/or diastolic blood pressure $\leq 60 \mathrm{~mm} \mathrm{Hg}$ and age $\geqslant 65$ years; NPV, negative predictive value; PPV, positive predictive value; SEWS, standardised early warning score; SIRS, systemic inflammatory response syndrome. 
Table 4 Clinical predictors of development of complicated parapneumonic effusion or empyema: final multivariate model

\begin{tabular}{lcllcl}
\hline Clinical feature & No & CPE/Emp (\%) & $\begin{array}{l}\text { Uncomplicated } \\
\text { pneumonia (\%) }\end{array}$ & AOR (95\% CI) & p Value \\
\hline Albumin $<30 \mathrm{~g} / \mathrm{l}$ & 144 & 38.0 & 9.3 & $4.55(2.45$ to 8.45$)$ & $<0.0001$ \\
CRP $>100 \mathrm{mg} / \mathrm{l}$ & 948 & 97.8 & 72.9 & $15.7(3.69$ to 66.9$)$ & 0.0002 \\
Platelet count $>400 \times 109 / 1$ & 157 & 31.5 & 10.9 & $4.09(2.21$ to 7.54$)$ & $<0.0001$ \\
Sodium $<130 \mathrm{mmol} / \mathrm{l}$ & 105 & 19.6 & 7.4 & $2.70(1.55$ to 4.70$)$ & 0.0005 \\
Intravenous drug use & 38 & 10.9 & 2.4 & $2.82(1.09$ to 7.30$)$ & 0.03 \\
Chronic alcohol abuse & 70 & 13 & 4.9 & $4.28(1.87$ to 9.82$)$ & 0.0006 \\
COPD & 257 & 4.3 & 21.5 & $0.18(0.06$ to 0.53$)$ & 0.002 \\
\hline
\end{tabular}

AOR, adjusted odds ratio; COPD, chronic obstructive pulmonary disease; CPE/Emp, complicated parapneumonic effusion or empyema; CRP, C-reactive protein.

dampened response when exposed to an acute bacterial challenge..$^{25}$ The acute administration of steroids is another important potential confounding factor. Steroids have potent effects on attenuating pulmonary and systemic inflammation ${ }^{26}$ and may also attenuate pleural inflammation.

The widely used pneumonia severity and sepsis severity scores considered in this study were not found to be useful for predicting the development of complicated parapneumonic effusion or empyema. The clinical features that predispose to 30-day mortality from pneumonia are clearly different from those identified in this study to predispose to the development of complicated parapneumonic effusion or empyema. Of the risk factors identified in this study, only hypoalbuminaemia, hyponatraemia and an elevated CRP have been identified as independent risk factors for mortality, and none of these is among the "core" high risk features carrying the greatest risk of death.

This study found that the $S$ milleri group was the most frequently isolated organism in patients with empyema, followed by other streptococci. This is consistent with the findings of the UK trial of intrapleural streptokinase and a recent study of patients with community-acquired pleural infection from Canada. ${ }^{27} 28$

However, $82 \%$ of patients had no organisms cultured. The frequency of positive microbiological diagnosis in this study is lower than in many other published studies of empyema, which have reported a microbiological diagnosis in between $40 \%$ and $60 \%$ of cases. ${ }^{29-32}$ Several factors may account for this; first, many of these studies have reported positive blood cultures in addition to positive fluid microbiology ${ }^{29}$ rather than simply positive pleural fluid cultures, which is the case in this study. Many studies have focused exclusively on empyema and consequently reported a much higher incidence of patients

Table 5 Risk stratification using a derived score for prediction of complicated parapneumonic effusion or empyema

\begin{tabular}{lccc}
\hline No patients & & & \\
\hline Points & CPE/Emp & Uncomplicated pneumonia & $\%$ \\
\hline-1 & 0 & 66 & 0 \\
0 & 1 & 296 & 0.003 \\
1 & 11 & 442 & 2.4 \\
2 & 38 & 283 & 11.8 \\
3 & 28 & 81 & 25.7 \\
4 & 12 & 7 & 63.2 \\
5 & 2 & 2 & $50^{*}$ \\
6 & 0 & 0 & - \\
\hline${ }^{*} \chi^{2}, p<0.0001$. &
\end{tabular}

CPE/Emp, complicated parapneumonic effusion or empyema. with frankly purulent effusions, ${ }^{27-30}$ which may be more likely to give a positive result. In addition, prior antibiotic treatment is likely to play a role, as empirical treatment in communityacquired pneumonia covers the majority of potential organisms, whereas in other studies the aetiology of empyema is variable and it cannot be said with certainty whether empirical treatment was effective against the organisms isolated.

\section{Limitations}

Although the clinical assessment of patients in this study was comprehensive, 27 patients had pleural effusions that were not sampled, because thoracic ultrasound indicated insufficient pleural fluid to tap safely. As all patients were followed up, we feel that it is unlikely that clinically important cases of pleural infection were missed.

This study represents a large cohort of patients with community-acquired pneumonia; the numbers developing the outcome of interest ( 92 patients in total) were relatively small,

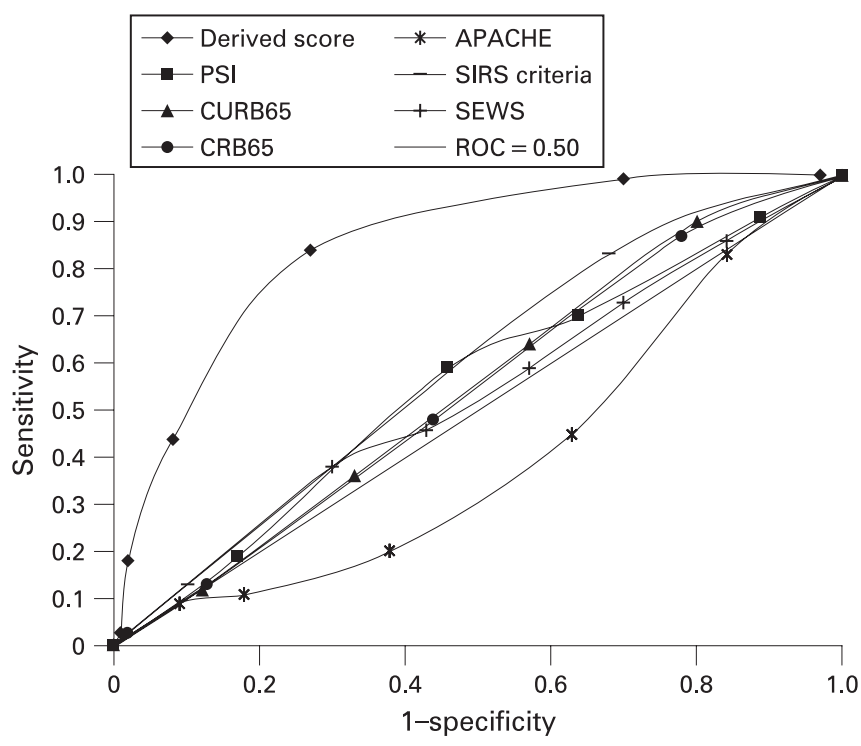

Figure 4 Receiver operator characteristic (ROC) curve for the derived risk score and prediction of complicated parapneumonic effusion or empyema. APACHE II, Acute Physiology and Chronic Health Evaluation II; CRB65, New onset confusion, Respiratory rate $\geqslant 30$ breaths/min, Systolic blood pressure $<90 \mathrm{~mm} \mathrm{Hg}$ and/or diastolic blood pressure $\leq 60 \mathrm{~mm} \mathrm{Hg}$ and age $\geqslant 65$ years; CURB65, New onset confusion, urea $>7 \mathrm{mmol} / \mathrm{l}$, Respiratory rate $\geqslant 30$ breaths/min, Systolic blood pressure $<90 \mathrm{~mm} \mathrm{Hg}$ and/or diastolic blood pressure $\leq 60 \mathrm{~mm} \mathrm{Hg}$ and age $\geqslant 65$ years; SEWS, standardised early warning score; SIRS, systemic inflammatory response syndrome. 
and this is reflected in the wide confidence intervals for some of the individual predictors. Multicentre studies would be required to define the relative risks more accurately.

Athough the performance of the derived predictive score is defined as "good" (AUC 0.84) in our study population, prospective validation is required before any recommendations can be made about its use in clinical practice.

\section{Conclusion}

There are important differences in the presentation of patients with complicated parapneumonic effusion and empyema compared with patients with uncomplicated communityacquired pneumonia. Pneumonia and generic sepsis scores do not predict the development of these complications, but a simple 6-point scoring system can allow identification of high risk patients. Independent validation studies are needed.

Funding: JDC is supported by a Clinical Research Training Fellowship from the Medical Research Council.

Competing interests: None.

Ethics approval: Ethics approval was obtained from the Lothian Research Ethics Committee.

\section{REFERENCES}

1. Taryle DA, Potts DE, Sahn SA. The incidence and clinical correlates of parapneumonic effusions in pneumococcal pneumonia. Chest 1978;74:170-3.

2. Davies CWH, Gleeson FV, Davies RJO. BTS guidelines for the management of pleural infection. Thorax 2003;58(Suppl 2):ii18-28.

3. Davies CW, Kearney SE, Gleeson FV, et al. Predictors of outcome and long term survival in patients with pleural infection. Am J Respir Crit Care Med 1999;160:1682-7.

4. Light RW, Girard WM, Jenkinson SG, et al. Parapneumonic effusions. Am J Med 1980;69:507-12.

5. Lim WS, Van Der Eerden MM, Laing R, et al. Defining community acquired pneumonia severity on presentation to hospital: an international derivation and validation study. Thorax 2003:58:377-82.

6. Ewig S, Ruiz M, Mensa J, et al. Severe community-acquired pneumonia: assessment of severity criteria. Am J Respir Crit Care Med 1998;158:1102-8.

7. Fine MJ, Auble TE, Yealy DM, et al. Prediction rule to identify low risk patients with community acquired pneumonia. N Engl J Med 1997;336:243-50.

8. Capelastegui A, Espana PP, Quintana JM, et al. Validation of a predictive rule for the management of community-acquired pneumonia. Eur Respir J 2006;27:151-7.

9. Chalmers JD, Singanayagam A, Hill AT. Systolic blood pressure is superior to other haemodynamic predictors of outcome in community acquired pneumonia. Thorax 2008;63:698-702.
10. Knaus WA, Draper EA, Wagner DP, et al. Apache II: a severity of disease classification system. Crit Care Med 1985;13:818-29.

11. Bone RC, Balk RA, Cerra FB, et al. Definitions for sepsis and organ failure and guidelines for the use of innovative therapies in sepsis. Chest 1992;101:1644-55.

12. Subbe CP, Kruger $M$, Rutherford $P$, et al. Validation of a modified early warning score in medical admissions. OJM 2001;94:521-6.

13. Allison PD. Logistic regression using the SAS system. Cary, NC: SAS Institute, 1999

14. DeLong ER, DeLong DM, Clarke-Pearson DL. Comparing the areas under two or more correlated receiver operator characteristic curves: a nonparametric approach. Biometrics 1998;44:837-45.

15. LeMense GP, Strange C, Sahn SA. Empyema thoracis: therapeutic management and outcome. Chest 1995;107:1532-7.

16. Alfagame I, Munoz F, Pena N, et al. Empyema of the thorax in adults: etiology, microbiologic findings and management. Chest 1993;103:839-43.

17. Chung $\mathbf{C L}$, Chen $\mathrm{CH}$, Sheu JR, et al. Proinflammatory cytokines, transforming growth factor-beta1 and fibrinolytic enzymes in loculated and free flowing pleural exudates. Chest 2005;128:690-7.

18. Chalmers JD, Singanayagam A, Hill AT. C-reactive protein is an independent marker of severity in community acquired pneumonia. Am J Med 2008;121:219-25.

19. Hansson LO, Hedlund JU, Ortqvist AB. Sequential changes of inflammatory and nutritional markers in patients with community-acquired pneumonia. Scand J Clin Lab Invest 1997:57:111-8.

20. Icard P, Fleury JP, Regnard JF, et al. Utility of C-reactive protein measurements for empyema diagnosis after pneumonectomy. Ann Thorac Surg 1994;57:933-6.

21. Klinger $\mathbf{M H}$, Jelkmann $\mathbf{W}$. Role of blood platelets in inflammation and infection. J Interferon Cytokine Res 2002;22:913-22.

22. Petty BG, Smith CR. The syndrome of inappropriate secretion of antidiuretic hormone associated with anaerobic thoracic empyema. Am Rev Respir Dis 1977;115:685-8.

23. Fine MJ, Smith MA, Carson CA, et al. Prognosis and outcomes of patients with community-acquired pneumonia. A meta-analysis. JAMA 1996;275:134-41.

24. Cham CW, Haq SM, Rahamim J. Empyema thoracis: a problem with late referral? Thorax 1993;48:925-7.

25. Torres A, Menendez R. Mortality in COPD patients with community-acquired pneumonia: who is the third partner? Eur Respir J 2006;28:262-3.

26. Montón C, Ewig S, Torres A, et al. Role of glucocorticoids on inflammatory response in nonimmunosuppressed patients with pneumonia: a pilot study. Eur Respir $J$ 1999;14:218-20.

27. Maskell NA, Davies CW, Nunn AJ, et al. UK controlled trial of intrapleural streptokinase for pleural infection. N Engl J Med 2005;352:865-74.

28. Ahmed R, Marrie TJ, Huang JO. Thoracic empyema in patients with community acquired pneumonia. Am J Med 2006;119:877-83

29. Bouros D, Schiza S, Tzanakis N, et al. Intrapleural urokinase versus normal saline in the treatment of complicated parapneumonic effusions and empyema. a randomized, double-blind study. Am J Respir Crit Care Med 1999;159:37-42

30. Davies CW, Kearney SE, Gleeson FV, et al. Predictors of outcome and long-term survival in patients with pleural infection. Am J Respir Crit Care Med 1999;160:1682-7.

31. Chin NK, Lim TK. Controlled trial of intrapleural streptokinase in the treatment of pleural empyema and complicated parapneumonic effusions. Chest 1997;111:275-9

32. Lindstrom ST, Kolbe J. Community acquired parapneumonic thoracic empyema: predictors of outcome. Respirology 1999;4:173-9

\section{Access a vast information database with Toll-Free linking}

"Toll-free" linking gives you immediate access to the full text of many of the cited articles in a paper's reference list-FOR FREE. With the support of HighWire's vast journal catalogue, a huge reference library is now open to you. If HighWire hosts the journal, you can view the full text of the referenced article, completely free of charge by following the Free Full Text links in the references. 